\title{
As mulheres e as práticas corporais em clubes da cidade de São Paulo do início do século XX
}

\author{
Milena Bushatsky Mathias \\ Katia Rubio
}

https://doi.org/10.5628/rpcd.09.02-03.195

Departamento de Pedagogia do Movimento do Corpo Humano Escola de Educação Física e Esporte

Universidade de São Paulo

Brasil

\begin{abstract}
The women and the corporal practices at Sao Paulo city clubs during the beginning of 20th century

The woman condition at 20's was determined by a discourse that, based in the public life and dedication to a private life. At the same time the Feminist Movement fight to the rights of the women to citizenship and a social life outside. Among Physical Education, the discourses added a woman physically active. The athletics', classic dance and basketball started to be consider health activities to women. The subjective of this paper is to discuss how it was the women participation at the corporal practices in clubs at 20's of 20th Century in Sao Paulo.
\end{abstract}

Palavras-chave: feminismo, práticas corporais, emancipação, esporte e mulher

\begin{abstract}
No Brasil a condição feminina na década de 1920 era determinada pela exclusão da vida pública e dedicação a vida privada. Neste mesmo período o movimento feminista lutou pelo direito das mulheres à cidadania, a uma existência legal fora de casa. Na Educação Física os discursos apontam uma mulher fisicamente ativa, dentro de propósitos eugenistas e higienistas. O atletismo, a dança clássica e o basquetebol começaram a ser considerados atividades saudáveis para mulheres. O objetivo deste trabalho é discutir como se deu a participação da mulher nas práticas corporais em clubes na década de 1920 na cidade de São Paulo.
\end{abstract}

Key-words: feminism, corporal practices, emancipation, sport and woman 


\section{INTRODUÇÃO}

O século XX representa um marco para o movimento feminista por transformar radicalmente discursos e práticas sobre a condição da mulher na sociedade. Em função da cristalização de papéis sociais a mulher se viu desumanizada enquanto sujeito histórico, protagonizando apenas o papel social de "mãeesposa-dona de casa".

Essa condição ganhou amparo legal com o código civil de 1916, que subordinava a mulher ao homem, legalizando uma dependência e subordinação que já eram defendidas com argumentos biológicos. Dessa forma, restava à mulher desempenhar actividades da esfera da vida privada, sendo atribuídas a ela as funções de casar, gerar filhos para a pátria e plasmar o carácter dos cidadãos de amanhã ${ }^{(9)}$. E assim firmavase a oposição entre as esferas pública e privada, definindo os papéis sociais masculino e feminino, de acordo com as expectativas e imposições sociais. Nesse mesmo período o Movimento Feminista viveu um momento de intensa organização e actuação, ainda que fragmentado e dependente de esforços individuais, ganhando visibilidade em defesa dos direitos da mulher. Entre suas bandeiras de luta estavam o direito ao voto, a educação e o acesso ao mercado de trabalho.

Entendendo que as práticas corporais de movimento acompanham a dinâmica social, este trabalho tem como objectivo investigar o processo de inclusão das mulheres na cultura corporal de movimento na cidade de São Paulo durante a década de 1920. Esse recorte histórico justifica-se pela importância desse período para o Movimento Feminista no Brasil, pela história da Educação Física brasileira e para as conquistas das mulheres ao longo do século XX. O referencial teórico utilizado para análise é da epistemologia feminista, na qual as mulheres são percebidas como sujeitos sociais e políticos, e também como sujeitos do conhecimento.

Segundo Louro(8), isso expõe conexões e imbricações ocultas entre o público e o privado, permitindo que se observem vínculos de poder antes desprezados.

Foram tomadas como fontes primárias relacionadas a participação das mulheres em práticas corporais periódicos, fotos, jornais e documentos de época, consultados nos centros pró-memória do Clube Esperia, do Esporte Clube Pinheiros e do Clube Atlético Paulistano.
Os periódicos são uma importante fonte para a compreensão da contrariedade dos discursos acerca da presença feminina em atividades físicas. Ora exaltavam a performance das atletas dos clubes e divulgavam imagens das sportswomen de outros países, ora reafirmavam os propósitos eugenistas e higienistas da Educação Física feminina proposta por Fernando de Azevedo'.

As modalidades encontradas nos periódicos foram o ténis, o atletismo, a natação, o basquetebol, a dança clássica e os jogos presentes em actividades sociais. Para finalidade desse artigo abordaremos apenas o atletismo, a bola ao cesto e os jogos presentes em actividades sociais.

\section{A CONCILIAÇÃO DAS NOVAS DEMANDAS À VELHA ESTRUTURA SOCIAL}

O final do império, final da escravidão e início da republica representaram um importante cenário para o Brasil do início do século XX. As perspectivas de reestruturação das relações de trabalho em novas bases, a transição do sistema económico agrário para o fabril, a ampliação e a complexificação dos espaços urbanos, o aumento significativo da imigração, entre outros aspectos, sinalizavam o advento de um novo tempo. Também eram formuladas e executadas novas estratégias de disciplinarização e de representação dos corpos, que correspondiam as expectativas e interesses dominantes e apontavam para uma nova ética do trabalho e novos padrões de moralidade para os comportamentos afectivos, sexuais e sociais. A ciência despontava como paradigma e a medicina social oferecia as justificativas para a determinação de papéis e espaços sociais femininos e masculinos. Por razões biológicas, eram asseguradas como características das mulheres a fragilidade, o recato, o predomínio das faculdades afectivas sobre as intelectuais e a subordinação da sexualidade a vocação maternal. A gestação e a maternidade eram as justificativas para esses cuidados.

Essas características eram suficientes para justificar que se exigisse das mulheres uma atitude de submissão, um comportamento que não maculasse sua honra. Estavam impedidas do exercício da sexualidade antes de se casarem e, depois, deviam restringi-la ao âmbito desse casamento com a finalidade de gerar filhos. As mulheres, segundo Engel(4), dotadas de intenso erotis- 
mo e forte inteligência seriam despidas do sentimento de maternidade, característica inata da mulher normal, e deveriam ser afastadas do convívio social.

A imagem idealizada de mulher, possível para as elites urbanas, também foi exigida das camadas populares, muito embora a condição económica não favorecesse essa identificação. Isso porque a inserção das mulheres no mercado de trabalho se deu em função da necessidade de suprir as demandas da industrialização e também para auxiliar na complementação da renda familiar(13). No início da industrialização brasileira era significativo o número de mulheres e crianças nas fábricas, principalmente de fiação e tecelagem, representando a maioria da força de trabalho, por ser abundante e barata(11). Colaborou para essa situação as necessidades geradas pela Primeira Guerra Mundial, como o afastamento dos homens da vida produtiva e a necessidade de produção de suprimentos de todas as ordens. Após esse período, as mulheres foram progressivamente expulsas das fábricas, na medida em que avançava a industrialização e a re-incorporação da força de trabalho masculina.

A variação salarial, bem como a intimidação física, a desqualificação intelectual e o assédio sexual, eram algumas das barreiras enfrentadas pelas mulheres para participar do mundo do trabalho. Destaca-se, nesse contexto, a frequente associação entre a mulher no trabalho e a questão da moralidade(11). "Nas denúncias dos operários militantes, dos médicos higienistas, dos juristas, dos jornalistas, a fábrica é descrita como 'antro da perdição', 'bordel' ou 'lupanar', enquanto a trabalhadora é vista como uma figura totalmente passiva e "indefesa" (p. 585). Essa visão estava associada, directa ou indirectamente, a intenção de direccionar a mulher à esfera da vida privada.

Diante das necessidades impostas pelo contexto histórico a sociedade passou a divulgar a necessidade de uma nova esposa, mais moderna, mais consciente, menos subjugada a tirania do marido, mas nem por isso menos dedicada ao lar e a família

"A maternidade ganha ares de profissão, baseada em habilidades altamente qualificadas e especializadas e se toma o valor central das mulheres das famílias de classe média e alta" (3, p.66)
Na segunda metade do século XIX e nas primeiras décadas do século XX, as lutas e manifestações esparsas do movimento pelo direito das mulheres cederam lugar a uma campanha mais orgânica pelos direitos políticos de votarem e de serem votadas. O movimento sufragista espalhou-se pela Europa e pelos Estados Unidos, construindo a primeira vaga de feminismo organizado no mundo(10)2.

Os movimentos europeus e norte-americanos exerceram uma grande influência sobre as mulheres latinoamericanas. No Brasil, a primeira fase do feminismo, que abrangeu o final do século XIX e as três primeiras décadas do século XX, esteve intimamente associada a personalidades. Mesmo quando apresentou algum grau de organização, essa derivava do esforço pessoal de alguma mulher, que por sua excepcionalidade, na maioria das vezes intelectual, rompia com os papéis para ela estabelecidos e se colocava no mundo público em defesa dos direitos femininos.

\section{AS PRÁTICAS CORPORAIS E O FEMININO}

O comportamento no âmbito das práticas corporais não se encontra isolado da dinâmica social, mas é reflexo das relações estabelecidas nesse espaço maior. Portanto, a prática de actividades físicas na década de 1920 pode ser observada como um microcosmo, dentro do macrocosmo que era a sociedade paulistana do final da Primeira República.

Nesse período, a disseminação das práticas corporais - cada vez mais presentes em clubes e escolas estava intimamente ligada ao controle corporal, ou seja, as preocupações higiénicas, eugênicas, médicas, morais e disciplinares. Dessa forma, havia uma nítida distinção entre as práticas aconselhadas a mulheres e homens, de forma que a preparação física reforçava as características corporais e comportamentais que distinguiam a ambos.

"Sob a cobertura do 'natural', uma disciplina dos corpos masculinos se impõe: os rapazes parecem ser espontaneamente atraídos pela competição, pelo treinamento físico e pelo desenvolvimento muscular, já que tudo isso só reforça neles a virilidade e, por conseqüência, a 'natureza' máscula" (12, p. 37-38).

Assim, esperava-se que os jovens seguissem a actualidade esportiva, participassem dos acontecimentos 
organizados nos estádios, torcessem por um time de futebol, se preocupassem com sua forma física e, sobretudo, praticassem esportes.

O discurso sobre a prática de actividades físicas por mulheres - que afirmava a inaptidão da constituição física feminina - sofreu transformações no início do século XX.

Visando a produção da "nova mulher", que deveria acompanhar os desafios da modernidade, deixava-se de valorizar a debilidade e a indolência feminina, assim como o ócio e a preguiça passaram a conformar o mal da alma e deveriam ser substituídos pela vitalidade do corpo e pela capacidade de resistir as intempéries da vida(4).

Essa transformação do pensamento da época exigiu uma grande dedicação por parte de alguns intelectuais que buscavam relacionar as benesses físicas e morais da ginástica feminina com o engrandecimento geral da nação. Dentre eles, Fernando de Azevedo teve um importante papel por sua longa trajetória científico-literária, na qual destacam-se $D a$ Educação Physica e Antinous: estudo de cultura atlhetica, ambos publicados em 1920. Nessas obras procurou construir uma doutrina pedagógica para a Educação Física brasileira condizente com o prestigio social dos métodos ginásticos europeus, mais especificamente com os pressupostos higienistas e eugenistas que os fundamentavam(5).

Fernando de Azevedo pensava a Educação Física como uma acção científica, "inserida dentro de um plano nacional de educação, que desenvolveria ao máximo a virilidade, as virtudes da raça e as aptidões hereditárias de cada individuo." (6, p.161). Buscava-se a eliminação da fraqueza orgânica, que além de debilitar cada sujeito por ela atingido, também debilitava a ideia de uma nação poderosa.

Ainda que fossem várias as restrições impostas e os cuidados a serem seguidos, Fernando de Azevedo atribuía grande importância aos exercícios corporais femininos para a formação das "obreiras da vida". Essa concepção apontava a maternidade como a mais nobre missão da mulher, pois dela dependia a regeneração da sociedade. Ainda assim, a aceitação de mulheres em esportes e outras actividades físicas vivia a dualidade entre as propostas eugenistas e higienistas, e certas características comuns ao universo da cultura física - como o suor excessivo, o esforço físico, as emoções fortes, as competições, a rivalidade consentida, os músculos delineados, os perigos das lesões e a leveza das roupas - que, quando relacionados a mulher, despertavam suspeitas por parecerem abrandar certos limites que contornavam uma imagem ideal de ser feminina.

A definição desses limites baseava-se na compreensão naturalizada do que e ser homem e do que e ser mulher, de acordo com as imposições e expectativas sociais. Considerava-se, então, que

"a resistência dos braços, a solidez do punho, que tem tanta importância para o homem, tem, para a mulher, importância extraordinariamente menor do que o desenvolvimento da bacia. E impossivel desconhecer e não seria licito na educação por de lado a constituição ou o sexo e submeter a juventude, como em Esparta, e agora na Escócia, aos mesmos exercícios; e se importa ter o maior cuidado da organização delicada das meninas, (...) a educação física da mulher deve ser, portanto, integral, higiênica e plástica, e, abrangendo com os trabalhos manuais os jogos infantis, a ginástica educativa $e$ os esportes, cingir-se exclusivamente aos jogos e esportes menos violentos e de todo em todo compativeis com a delicadeza do organismo das mães, como sejam entre estes a dança ao ar livre e a natação, a que deve preceder um curso regular de ginástica inteligentemente administrada"(1, p.82-33).

A dança era a única pratica corporal permitida as mulheres no século XIX, sobretudo as danças litúrgicas, que conferiam a bailarina um caráter quase sagrado. Porém, no início do século XX, de acordo com as idéias defendidas por Fernando de Azevedo, ela foi concebida como "um método de educação corporal feminina baseado na assimilação de um código de movimentos tidos como belos, harmoniosos e graciosos, que permitem às mocinhas a expressão - totalmente 'espontânea' - de sua 'natureza' feminina" (12, p.45).

Frequentemente realizada ao ar livre, visando o contacto com a natureza e a valorização do seu aspecto higiénico, tratava-se do treinamento dos gestos para assegurar que a espontaneidade não estragasse $o$ efeito desejado, objectivando o "controle absoluto sobre o corpo".

A ginástica feminina, segunda prática apontada por Fernando de Azevedo como adequada as mulheres, 
foi profundamente influenciada pela dança. Isso porque era necessária à preparação física dos bailarinos, dos quais se exigia flexibilidade, destreza, leveza nos saltos etc. A maior parte dos dirigentes de escolas de bailado da Europa criou formas de trabalho físico que foram sistematizadas e difundidas em outros países, originando a chamada ginástica feminina. Sua característica monótona, repetitiva, contrária a espontaneidade e controladora das "tendências corporais e psíquicas", fez com que a ginástica estivesse fortemente assimilada as práticas corporais femininas. Além disso, a ginástica era valorizada por ser completamente despida de competitividade, agressividade, desejo de vitória, desfavorecendo o desenvolvimento da ambição individual.

Uma outra prática destacada como fundamental a manutenção da saúde feminina era a caminhada, ou seja, andar a pé ou correr pequenas distâncias, sobretudo no campo. Valorizava-se essa prática pelo aspecto higiénico das saídas ao ar livre e pelo desenvolvimento muscular pouco significativo, já que um simples passeio era considerado suficiente.

A última prática apontada por Fernando de Azevedo é a natação, que se justificava como adequada às mulheres por proporcionar a harmonia plástica do corpo e inspirar a graça dos movimentos. Além disso, era ressaltada nesta prática a necessidade de intuição de ritmo, relacionada ao sexto sentido feminino, e a inconstância do meio líquido, que se assemelhava a alma da mulher e por isso as atraía mais do que aos homens(12).

Apesar do nascimento da natação feminina competitiva só ocorrer na década seguinte, foram presenciadas na década de 1920 tímidas tentativas de aparições públicas de nadadoras.

"Em São Paulo, coube a um pequeno grupo de moças da colônia alemã romper as maiores barreiras antepostas a mulher no desporto pelos costumes e preconceitos locais, ao se apresentar em público para nadar, ainda que envoltas em prodigiosos costumes de banho, abundantes em dobras e babados. As restrições encontradas em casa por estas jovens eram menores, porque elas advinham de uma cultura tradicionalmente adepta aos cuidados como físico e a apreciação dos encantos da natureza" (7, p17).

\section{AS PRÁTICAS CORPORAIS DE MOVIMENTO EM CLUBES DE SÃO PAULO}

Os periódicos da época apontam o atletismo como uma prática esportiva na década de 1920 . Os registos restringem-se a duas menções em edições da Revista Esperia - nas quais há notas sobre o desenvolvimento do esporte no clube, publicadas na coluna "Indiscrições" - e algumas fotos.

A primeira nota trata do grande interesse que os treinos femininos estavam despertando nos frequentadores do clube, o que pode justificar-se pela modalidade ser tradicionalmente uma prática masculina. "Mas as moças que estão em treino pouco se incomodam com os basbaques; visam apenas fortalecer seu physico, $e$ fazer brilhante figura, obtendo bons resultados"(14).

Percebe-se o reconhecimento de que há um envolvimento efectivo dessas mulheres com sua prática, condição essencial para que elas apresentassem um bom desempenho e ampliassem suas possibilidades de actuação na modalidade.

Porém, de acordo com a segunda nota, nem todos os espaços apresentavam condições favoráveis ao crescimento do atletismo feminino:

A Federação de Athletismo, com esse negócio de competiçôes femininas, parece que esta "tapeando" o pessoal. Marcam a competição para um certo dia, e dahi a pouco, ja noticiam a transferência. Depois, a data é alterada novamente. E assim pouco a pouco vão desanimando as pequenas que estão treinando. (16)

O posicionamento da Federação reforça a ideia de que a discriminação de género nos esportes se apresentava de forma cada vez mais velada. Isso porque não se assumia uma posição contrária a presença feminina nas pistas, mas eram elaboradas estratégias para desmobilização das atletas.

Embora os textos não se referissem especificamente as provas do atletismo, por meio das fotos e possível identificar mulheres participando do salto em altura, do arremesso de dardo e do arremesso de peso.

Outro aspecto que se destaca nas imagens é o uniforme, composto por uma camisa sem mangas e gola e um short. Esse uniforme se destaca de outros tipos de roupa utilizadas nas demais práticas corporais por ser extremamente apropriada a exercitação física.

Outra modalidade na qual as mulheres estavam pre- 
sentes era o basquetebol, praticado somente no Club Esperia e na Associação Athletica São Paulo. Assim como a disseminação dessa prática, as menções a participação feminina em publicações da época também eram poucas, restringindo-se a duas fotografias da equipe do Esperia e uma reportagem sobre a partida realizada entre os dois clubes.

Os uniformes utilizados para a prática do basquetebol apresentam-se de formas bastante distintas nas duas fotos da equipe feminina do Club Esperia. Em uma delas as atletas estão vestidas com saias pelos tornozelos, camisas com mangas compridas e punhos, as golas possuem laços e outros detalhes. $\mathrm{Na}$ outra foto, publicada no periódico do clube em 1929, as saias estão na altura dos joelhos, as camisas não possuem mangas e as golas não apresentam quaisquer ornamentos. O desconhecimento da data da primeira foto - encontrada nos arquivos do clube apenas com a especificação "década de 20 " - não nos permite inferir sobre uma possível conquista das atletas em relação aos trajes para a prática esportiva. A reportagem publicada na Revista Esperia, em $1929^{(15)}$, trata sobre o "encontro de bola ao cesto entre turmas femininas", que foi parte do programa de uma Semana de Educação Physica. O texto dessa publicação destaca-se dos demais escritos na época pela utilização de expressões pouco usuais na descrição de jogos em que havia a participação de mulheres.

O jogo foi disputado com muito ardor, chegando mesmo algumas vezes a assumir phases violentas, dando um trabalho insano ao juiz do encontro. Apesar disso, boas jogadas foram registradas, e belos lances a cesta resultaram em pontos, dos quaes a nossa turma fez a maior parte, assegurando-se deste modo a victoria das medathas oferecidas pela Comissão de Educacao Physica.

O relato desse jogo demonstra o intenso envolvimento das atletas com a modalidade e com a competição, o que, somado a rivalidade existente entre as duas equipes, proporcionou um acirramento da partida. Isso contraria a concepção de Fernando de Azevedo, que considerava adequadas às mulheres as actividades desprovidas do sentimento de competitividade. Outro aspecto que merece destaque neste excerto são os elogios tecidos à dimensão técnica e tática da partida, reconhecendo o valor das jogadoras pelo seu desempenho na modalidade. Também cabe destacar a premiação que congratulou as vencedoras com medalhas.

O texto da reportagem finaliza parabenizando as atletas pela atuação e fazendo considerações acerca da participação feminina nos esportes:

Seu exemplo é digno de merecer numerosas imitadoras, que um acanhamento injustificável afasta das competições esportivas, quando seria de desejar que o esporte feminino fosse desenvolvido paralelamente ao esporte masculino. As pioneiras da educação physica feminina por isso mesmo merecem maiores elogios, porquanto arrostam com os preconceitos, certas de agir bem. ${ }^{(15)}$

É de grande excepcionalidade para a época um homem manifestar-se publicamente para exaltar o desenvolvimento do esporte feminino com características similares ao masculino. Isso porque poucos consideravam adequado o envolvimento de mulheres em actividades físicas que proporcionassem um esforço intenso, contacto corporal e rivalidade consentida. Vale ainda destacar que, pelo que foi analisado, não se pode considerar injustificável o "acanhamento" de muitas mulheres, uma vez que eram constantemente elaboradas novas formas de dificultar seu acesso às actividades do mundo público. Entre essas formas estava a omissão, que pode ser exemplificada pela ausência de espaço que algumas modalidades femininas tinham na mídia da época. Em decorrência disso, há poucos registos da participação de mulheres em alguns esportes, dentre eles a esgrima, a ginástica, o vôlei, pólo aquático e o remo. Ainda havia eventos sociais promovidos pelos clubes nos quais as atividades físicas eram tomadas como uma forma de socialização da elite paulistana. Dentre eles, destacavam-se os five o'clock teas e as garden parties do Club Athetico Paulistano, onde as pessoas se reuniam e jogavam tênis, croque, diabolo, pingue-pongue, pelota e peteca. Esses encontros eram valorizados por se acreditar que "os diferentes jogos entre famílias traziam benefícios para a educação física das mocas" e ainda que "sem as mulheres, essas actividades se tornariam embrutecedoras"(2, p.26). Porém, essa atribuição da responsabilidade às mulheres pelo "desembrutecimento" das actividades supõe a delicadeza como uma característica inata a sua condição feminina. 
Gentis senhoritas e distintos rapazes, por sua vez, jogavam a peteca, considerada por muitos como nacional e que tem a vantagem de cansar menos. (..) Nas partidas de pingue-pongue, o sexo forte sempre foi derrotado. (17)

No excerto é abordada a adequabilidade da peteca à prática mista por sua reduzida exigência física, o que evidencia a equivocada compreensão de que o corpo feminino não deveria ser submetido a esforços intensos. Também é retomada a expressão "sexo forte" para referir-se ao homem, em oposição a mulher como o "sexo fraco", conforme discutido anteriormente.

O Club Athletico Paulistano, segundo o relatório anual de $1927^{(18)}$, possuía uma piscina tida como ponto de reunião diário de inúmeras famílias de associados. Porém, a utilização do espaço estava submetida a uma rígida divisão de horários: "Os homens ficavam a 'sós' entre as sete e as oito horas de segunda a sábado. As mulheres tinham a piscina a sua disposição as segundas, quartas e sextas, entre as oito e dez horas, e as terças, quintas e sábados, entre as dez e doze horas"(2, p. 39). O funcionamento da piscina em regime misto ocorria aos domingos e feriados, e das catorze as dezenove horas nos outros dias. No entanto, os relatórios anuais, o periódico e os livros sobre a historia do clube não apresentam qualquer justificativa para essa separação entre os sexos.

As festas ao ar livre do Club Esperia, segundo as fotografias publicadas no periódico do clube sob o titulo "Alguns aspectos da ultima festa do Club Esperia"(15) também contavam com actividades físicas, nas quais homens e mulheres participavam em provas separadas. As modalidades femininas fotografadas foram a corrida de cem metros para senhorinhas, o carrinho de mão e a corrida em sacos. Já os homens competiam no remo, corrida de três e cinco mil metros, corrida de revezamento, corrida em sacos e a prova surpresa.

Apesar do material referente a prática de actividades físicas por mulheres ser escasso, é evidente a ausência de um consenso sobre a aceitação feminina. Nas reportagens da época é possível perceber diferentes reacções a esse respeito: uns exaltavam, outros criticavam, havia os que silenciavam - por desmerecerem ou pela insegurança do porvir. Isso reflectia a instabilidade social gerada pelo avanço das mulheres em diversas áreas - nas artes, na política, no mercado de trabalho, na educação etc.

\section{CONSIDERAÇÕES FINAIS}

É importante ressaltar que os espaços e formas de exercitação física constituem um microcosmo da sociedade, e o que se verifica no campo das práticas corporais é uma intenção de conter o avanço das conquistas femininas. Há registos de que desde o século XIX algumas mulheres buscavam romper a resistência masculina exercitando-se em lugares públicos, ainda que se constituíssem em manifestações isoladas. A imagem que se veiculava delas correspondia aos valores de uma sociedade falocêntrica nomeando-as como prostitutas, loucas ou criminosas. Ainda assim, no início do século XX há uma intensificação da prática de actividades físicas por mulheres.

Uma solução encontrada para a manutenção do controle sobre o corpo feminino, inspirado no ideal nazista que se espalhava pela Europa de constituição de uma raça pura, foi limitar as possibilidades de práticas corporais, atribuindo a elas objectivos explicitamente higienistas e eugenistas. Dessa forma, as mulheres não faziam actividades físicas pelo seu direito a prática, pelo exercício de sua cidadania, mas para a construção de uma nação mais forte, com a qual elas contribuíam tendo filhos saudáveis, ou seja, exercendo aquilo que os homens consideravam sua principal função, a maternidade.

Ao tentar descrever uma versão à historia "oficial", reconstituindo a trajectória das mulheres na condição de protagonistas de suas acções, mostra que até meados dos século XX as mulheres tinham direito a uma vida pública restrita. Isso significava a impossibilidade de acesso a uma vida profissional, aos cargos políticos, a cultura e a educação, como também o desfrute de uma vida social publica. Além de serem consideradas incapazes de governar a si mesmas e aos outros, devendo, portanto, submeter-se a autoridade masculina em casa e fora dela, eram também excluídas do direito ao corpo e ao prazer sexual, sob pena de serem olhadas como anormalidades ou monstruosidades. Desse modo, "a grande conquista feminina e feminista do chamado 'século das mulheres', o XX, foi o direito a existência (grifo 
da autora), sem o que é impossível começar, se queremos um mundo fundado na justiça social, no respeito e na liberdade"(11, p.34). É possível afirmar que as experiências advindas da década de 1920 no que se refere tanto as práticas femininas recomendadas, quanto as que eram consideradas inadequadas, foram fundamentais para a ampliação das possibilidades de práticas corporais entre as mulheres brasileiras.

\section{NOTAS}

${ }^{1}$ Fernando de Azevedo é considerado o grande pensador do início da Educação Física brasileira. Afirmava a Educação Física como uma acção científica, "inserida dentro de um plano nacional de educação, que desenvolveria ao máximo a virilidade, as virtudes da raça e as aptidões hereditárias de cada indivíduo. Uma educação física que, pautada por um estatuto científico e ao mesmo tempo moral, estivesse articulada à medicina e às normas jurídicas em favor de uma nova ordenação dos corpos, constituindo, assim, uma consistente retórica corporal na qual estruturava sua proposta de 'corpo-nação' " (Goellner, 2004, p. 161).

2 Observa-se a Seneca Falls Convention, realizada em 1848, como um dos marcos do movimento sufragista nos EUA, que produziu a Declaração de Seneca Falls, conhecida como Declaration of Sentiments reivindicando a ampliação dos princípios da declaração de independência americana para as mulheres. Em 1869 foi fundada a National Woman Suffrage Association e a American Woman Suffrage Association por participantes da Seneca Falls Convention, ambas as associações organizaram movimentos de luta pelos direitos das mulheres de grande vulto no século XIX. A existência das distintas associações, porém com objetivos comuns, demonstra como o feminismo desde suas origens apresenta essa grande diversidade observada até os dias atuais. Grosso modo essas associações se diferenciavam pelas formas de ação que deveriam ser empreendidas na luta pelos direitos das mulheres. Em 1890 as duas associações se amalgamaram, sobrepondo as diferenças para fortalecer o movimento, formando a National American Woman Suffrage Association.

\section{REFERÊNCIAS}

1. Azevedo F (1960). Da Educacao Fisica - O que ela e, o que tem sido e o que deveria ser. Seguido de Antinous Estudo da cultura atlética e A evolução do esporte no Brasil. Obras Completas de Fernando de Azevedo. São Paulo: Melhoramentos, 33 edição.

2. Brandão EL (2000). Club Athletico Paulistano - Corpo e alma de um clube centenário 1900-2000. São Paulo, Editora DBA.

3. Bruschini C (1990). Mulher, Casa e Família. São Paulo: Vértice, Editora Revista dos Tribunais.

4. Engel M. (1997) Psiquiatria e Feminilidade. In: Priore MD Historia das Mulheres no Brasil. São Paulo: Contexto.

5. Goellner SV (2003). Bela, maternal e feminina: imagens da mulher na Revista Educação Physica. Ijui: Editora Unijui.

6. Goellner SV (2004). O Espetáculo do Corpo: Mulheres e Exercitação Física no Inicio do Século XX. In: Carvalho MJS \& Rocha CMF (Orgs.), Produzindo Gênero. Porto Alegre: Sulina.

7. Lenk M (1982). Braçadas e Abraços. Rio de Janeiro: Grupo Atlantica-Boa Vista.

8. Louro GL (1997). Gênero, sexualidade e educação. Petrópolis: Vozes.

9. Maluf M Mott ML. (1998) Recônditos do mundo feminino. In: Sevcenko N (Org.) História da vida privada no Brasil. República: da Belle Epoque a Era do Radio. São Paulo: Companhia das Letras.

10. Pinto CRJ (2003). Uma historia do feminismo no Brasil. São Paulo: Editora Fundação Perseu Abramo

11. Rago M (1997). Trabalho Feminino e Sexualidade. In: Priore MD, História das Mulheres no Brasil. São Paulo: Contexto.

12. Schpun MR (1999). Beleza em Jogo: Cultura física e comportamento em São Paulo nos anos 20. São Paulo: Boitempo.

13. Soihet R (1997). Mulheres pobres e violência no Brasil urbano. In: Priore MD, História das Mulheres no Brasil. São Paulo: Contexto.

14. Revista Esperia, ano 1, no 2, outubro/1928.

15. Revista Esperia, ano 1, n 10/11, julho - agosto/1929.

16. Revista Esperia, ano ifi, $\mathrm{n}^{\circ} 28$, fevereiro/1931.

17. Revista Mensal do Club Athletico Paulistano, ano 1, $\mathrm{n}^{\circ} 4$, dezembro/1927.

18. Revista Mensal do Club Athletico Paulistano, ano II, no 4, abril/1928.

\section{CORRESPONDÊNCIA}

\section{Katia Rubio}

Av. Prof. Mello Moraes, 65

Butantã

05508-900 - Sao Paulo, SP - Brasil

E-mail:katrubio@usp.br 